ARTICLE

DOI: $10.1038 / \mathrm{s} 41467-018-06831-9$

\title{
Manganese-catalyzed hydroboration of carbon dioxide and other challenging carbonyl groups
}

\author{
Christina Erken (10) 1,2, Akash Kaithal (10) 2, Suman Sen (10 2, Thomas Weyhermüller (10) ${ }^{1}$, Markus Hölscher (10) ${ }^{2}$, \\ Christophe Werlé (iD ${ }^{1} \&$ Walter Leitner (10 ${ }^{1,2}$
}

Reductive functionalization of the $\mathrm{C}=\mathrm{O}$ unit in carboxylic acids, carbonic acid derivatives, and ultimately in carbon dioxide itself is a challenging task of key importance for the synthesis of value-added chemicals. In particular, it can open novel pathways for the valorization of nonfossil feedstocks. Catalysts based on earth-abundant, cheap, and benign metals would greatly contribute to the development of sustainable synthetic processes derived from this concept. Herein, a manganese pincer complex $\left[\mathrm{Mn}\left(\mathrm{Ph}_{2} \mathrm{PCH}_{2} \mathrm{SiMe}_{2}\right)_{2} \mathrm{NH}(\mathrm{CO})_{2} \mathrm{Br}\right]$ (1) is reported to enable the reduction of a broad range of carboxylic acids, carbonates, and even $\mathrm{CO}_{2}$ using pinacolborane as reducing agent. The complex is shown to operate under mild reaction conditions $\left(80-120^{\circ} \mathrm{C}\right)$, low catalyst loadings $(0.1-0.2 \mathrm{~mol} \%)$ and runs under solvent-less conditions. Mechanistic studies including crystallographic characterisation of a borane adduct of the pincer complex (1) imply that metal-ligand cooperation facilitates substrate activation.

\footnotetext{
${ }^{1}$ Max-Planck-Institute for Chemical Energy Conversion, Stiftstraße 34-36, 45470 Mülheim an der Ruhr, Germany. ${ }^{2}$ Institut für Technische und Makromolekulare Chemie, RWTH Aachen University, Worringer Weg 2, 52074 Aachen, Germany. These authors contributed equally: Akash Kaithal, Suman Sen, Christina Erken. Correspondence and requests for materials should be addressed to W.L. (email: walter.leitner@cec.mpg.de)
} 
T he catalytic reduction of the $\mathrm{C}=\mathrm{O}$ unit in carboxylic acids $\left(\mathrm{RCO}_{2} \mathrm{H}\right)$, carbonic acid derivatives $\left(\mathrm{O}=\mathrm{C}(\mathrm{OR})_{2}\right)$, and ultimately carbon dioxide $\left(\mathrm{CO}_{2}\right)$ itself is of great current interest for the development of sustainable chemical value chains. It can enable novel synthetic pathways through manipulation of functional groups in fine chemical and pharmaceutical synthesis in line with the principles of Green Chemistry ${ }^{1-3}$. In particular, such transformations are of paramount importance also in the utilization of alternative feedstocks derived from biomass ${ }^{4-6}$ or from carbon dioxide $\mathrm{e}^{7-10}$. The use of molecular complexes of firstrow transition metals has gained increasing attention as potential catalysts for reduction reactions in this context ${ }^{11-22}$. These metals are in most cases more readily available at lower costs and in some cases also more environmentally benign as compared to noble metals from the platinum group that would be applied typically in such transformations. Manganese is emerging as a particularly interesting metal component, as it fulfills all the criteria above and has been described to exhibit catalytic activity especially in form of so-called pincer complexes for reduction of carbonyl units in challenging substrates in most recent studies ${ }^{23-30}$. In the present paper, we report a Mn pincer complex that enables catalytic reductive functionalization for a wide range of structurally divers substrates through hydroboration of free carboxylic acids, cyclic five- and six-membered carbonates, linear carbonates, and even carbon dioxide.

\section{Results}

Synthesis of Mn complex 1. The complex $\left[\mathrm{Mn}\left(\mathrm{Ph}_{2} \mathrm{PCH}_{2} \mathrm{Si}\right.\right.$ $\left.\mathrm{Me}_{2}\right)_{2} \mathrm{NH}(\mathrm{CO})_{2} \mathrm{Br}$ ] (1) was synthesized by treatment of $\mathrm{Mn}$ $(\mathrm{CO})_{5} \mathrm{Br}$ with one equivalent of 1,3-bis((diphenyl-phosphino) methyl)tetramethyldi-silazane ${ }^{31}$ in toluene at $100^{\circ} \mathrm{C}$ for $16 \mathrm{~h}$ (Fig. 1). Complex 1 was isolated as a yellow powder with $90 \%$ yield. All spectroscopic data are in the expected range (see Supplementary Information for details) and single crystals suitable for X-ray diffraction were obtained by slow diffusion of hexane into a concentrated solution of $\mathbf{1}$ in dichloromethane.

Reduction of carboxylic acids. Exploring the potential of complex $\mathbf{1}$ as a catalyst, we were very pleased to find that exhibited excellent activity in the reduction of a broad range of carboxylic acids with pinacolborane in the presence of $\mathrm{KO}^{\mathrm{t}} \mathrm{Bu}$ as base under neat conditions (Table 1). The hydroboration of free carboxylic acid remains otherwise largely elusive to date. Very recently, Gunanathan's group reported the Ruthenium-catalyzed hydroboration of carboxylic acids with pinacolborane to alkyl boronate esters that could be hydrolyzed to the corresponding alcohols ${ }^{32}$. Notably, this noble-metal complex is currently the only catalytic system that has been reported for this transformation except for complex 1.

The reaction conditions of the standard protocol shown in Table 1 were derived from a detailed screening using acetic acid (2b) as benchmark substrate (see Supplementary Table 1 and Supplementary Table 2). Both the manganese complex and the base were found to be essential components for significant conversion (i.e., for $\mathbf{2 b} \mathbf{b} \%$ of yield in the absence of base and $30 \%$ of yield in the absence of $\mathbf{1}$ ). $\mathrm{NEt}_{3}$ could also be used as base with good performance $(90 \%, 24 \mathrm{~h}$ ), while $\mathrm{NaOH}$ gave substantially lower yields $(39 \%, 24 \mathrm{~h})$. The use of solvents was found detrimental independent of their polarity or donor strength. The reaction reached $>99 \%$ yield within $20 \mathrm{~h}$ at catalyst loadings of $0.2 \mathrm{~mol} \%$ and higher and within $24 \mathrm{~h}$ even at $0.1 \mathrm{~mol} \%$.

Aliphatic acids (2a-i, $\mathbf{2 m}-\mathbf{q})$ were converted in very good to excellent yields independent of the chain length, including even the $\mathrm{C} 1$ compound formic acid (2a). Carbon-carbon double bonds were fully tolerated and not reduced (2f-g, 2q). Benzoic acid (2j) also reacted smoothly. The reduction was very selective even in<smiles>CO[Sb](C)(C)(C)CP(c1ccccc1)c1ccccc1</smiles>

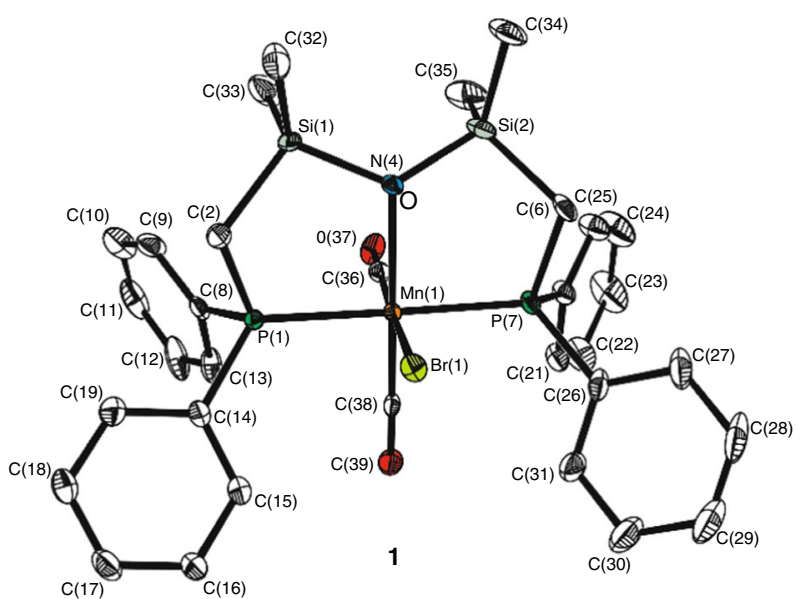

Fig. 1 Reaction scheme and molecular structure of complex 1. Overall geometry: distorted octahedral. Selected angles and atom distances: [P(1)-Mn(1)-P $\left.(7)=173.47^{\circ}\right],\left[C(36)-\mathrm{Mn}(1)-\mathrm{C}(38)=86.14^{\circ}\right]$. The $\mathrm{Mn}$ center is embedded in the P,N,P-pincer framework with bond lengths in the typical range $[(\mathrm{Mn}(1)-$ $\mathrm{P}(1)=229.97 \mathrm{pm} ; \mathrm{Mn}(1)-\mathrm{N}(4)=227.4 \mathrm{pm} ; \mathrm{Mn}(1)-\mathrm{P}(7)=230.22 \mathrm{pm}),(\mathrm{Si}(1)-\mathrm{N}(4)=177.0 \mathrm{pm}),(\mathrm{N}(4)-\mathrm{Si}(2)=177.1 \mathrm{pm})]$; and both P-Mn-N angles very close to $90^{\circ}\left(P(1): 88.32^{\circ}\right.$ and $P(7): 87.91^{\circ}$, respectively) 


\section{Table 1 Hydroboration of carboxylic acids using Mn complex 1 as catalyst}

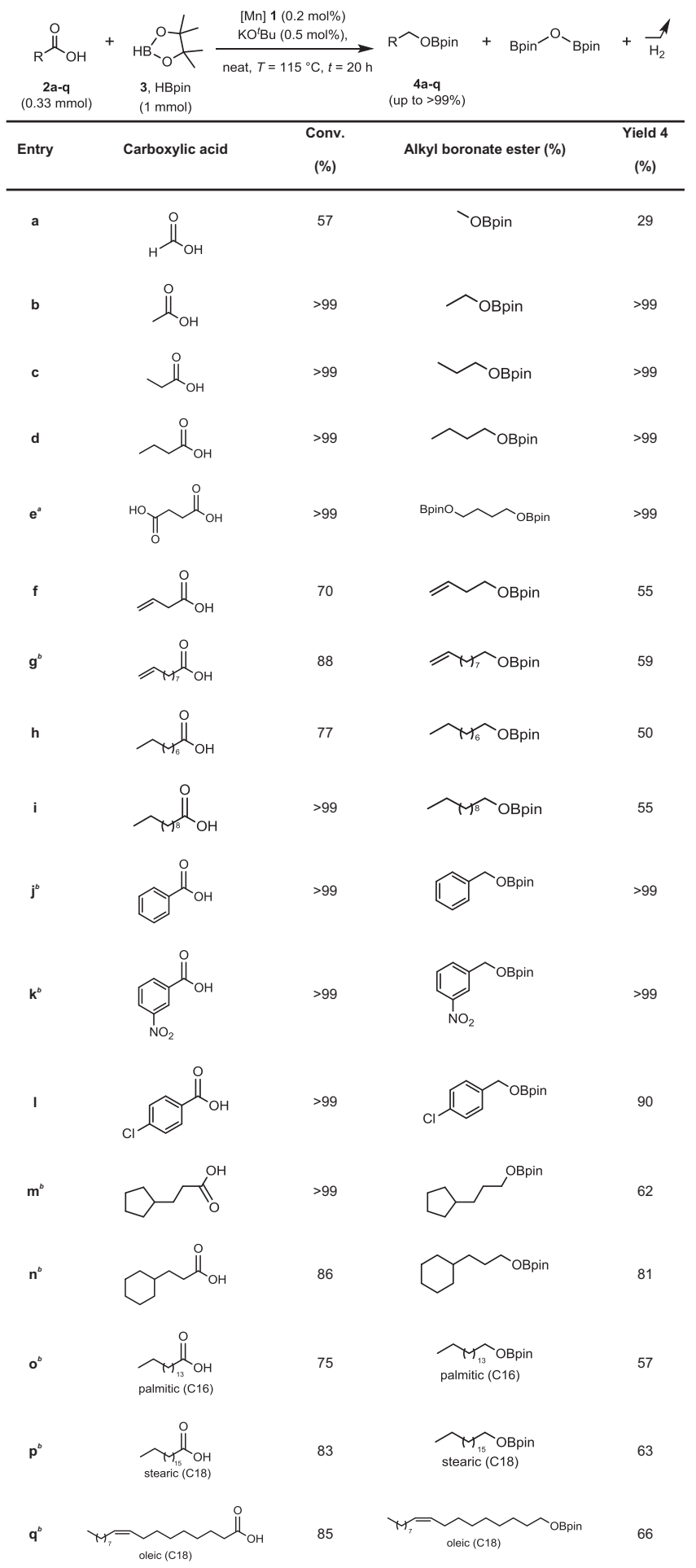

Yields were determined by ${ }^{1} \mathrm{H}$ NMR analysis using mesitylene as internal standard. Reaction conditions: $\mathbf{2}(0.33 \mathrm{mmol}), \mathbf{1}(0.2 \mathrm{~mol} \%), \mathrm{KO}^{\mathrm{t}} \mathrm{Bu}(0.5 \mathrm{~mol} \%)$ and $\mathbf{3}(1.0 \mathrm{mmol})$ at $115^{\circ} \mathrm{C}$ for $20 \mathrm{~h}$. $\mathbf{a}, \mathrm{Modified}$ conditions: $\mathbf{2 e}(0.33 \mathrm{mmol}), \mathbf{1}(0.2 \mathrm{~mol} \%), \mathrm{KO}{ }^{\mathrm{B}} \mathrm{Bu}(0.5 \mathrm{~mol} \%)$ and $\mathbf{3}(2.0 \mathrm{mmol})$ at $115^{\circ} \mathrm{C}$ for $36 \mathrm{~h} . \mathbf{b}$, Modified conditions: $\mathbf{2}(0.33 \mathrm{mmol}), \mathbf{1}(0.2 \mathrm{~mol} \%), \mathrm{KO} \mathrm{Bu}^{\mathrm{B}}(0.5 \mathrm{~mol} \%)$ and $\mathbf{3}(1.0 \mathrm{mmol})$ at $115^{\circ} \mathrm{C}$ for $24 \mathrm{~h}$

the presence of chloro (2l), or nitro groups (2k), albeit yield was somewhat lower under standard reaction conditions in the latter case. The biomass-derived platform chemical succinic acid (2e) was hydroborated in good yields upon adjustment of the stoichiometric ratio of the pinacolborane. The excellent results obtained with saturated and unsaturated aliphatic carboxylic acids prompted us to apply the Mn-catalyzed hydroboration also to fatty acids. Both saturated (2o-p) and unsaturated (2q) fatty 
acids were readily converted to the corresponding alkyl boronates in $57-66 \%$ yield after $24 \mathrm{~h}$. The integrity of the double bonds and their stereochemical arrangement was fully retained during this transformation.

Reduction of carbonates. The selective reduction of carbonic acid esters is very challenging as these compounds are kinetically very stable toward hydride addition. In fact, organic carbonates are frequently used as a solvent in catalytic reduction reactions ${ }^{33}$. Reduction of carbonates has gained additional interest as these compounds can be prepared from $\mathrm{CO}_{2}$ and $\mathrm{CO}$, leading to their reduction to methanol derivatives ${ }^{34,35}$. Cyclic carbonates can be envisaged also as protecting groups or synthetic precursors for the corresponding diols that are simultaneously liberated upon reductive cleavage ${ }^{36,37}$. The hydroboration of carbonates has not been described up to now, however.

Ethylene carbonate (5a) was chosen as a model substrate to screen for catalytic activity and identify a set of standard reaction conditions with catalyst $\mathbf{1}$ (see the Supplementary Information and Supplementary Table 3 for details). Reaction of ethylene carbonate $(1 \mathrm{mmol})$ with the stoichiometric equivalent of pinacolborane $(3 \mathrm{mmol})$ in the presence of complex $1(0.1 \mathrm{~mol} \%)$ and $\mathrm{NaO}^{t} \mathrm{Bu}(0.3 \mathrm{~mol} \%)$ at $90^{\circ} \mathrm{C}$ revealed formation of the boronate ester ethylene glycol already in $77 \%$ yield after $4 \mathrm{~h}$. Methyl boronate (4a), the actual reduction product from the central carbon of the carbonate group, was detected in $62 \%$ yield. No significant conversion was observed in absence of either 1 or base. Up to $97 \%$ yield could be achieved at higher loadings of complex 1 and base ( 0.25 and $0.4 \mathrm{~mol} \%$, respectively). The yield could be increased to practically the same level of $95 \%$ also at the initial lower loadings upon prolonging the reaction time to $8 \mathrm{~h}$. These conditions were chosen to assess the substrate scope of this catalytic transformation.

As summarized in Table 2, various carbonates including cyclic and linear structures were reduced to the corresponding hydroboration product. All reactions were carried out under solvent-free conditions. Five-membered ring carbonates $(\mathbf{5 a}-\mathbf{c})$ gave excellent yields between 95 and $97 \%$ similar to ethylene carbonate. Interestingly, the 1,2-carbonate of glycerol (5d), which

Table 2 Hydroboration of carbonates using Mn complex 1 as catalyst

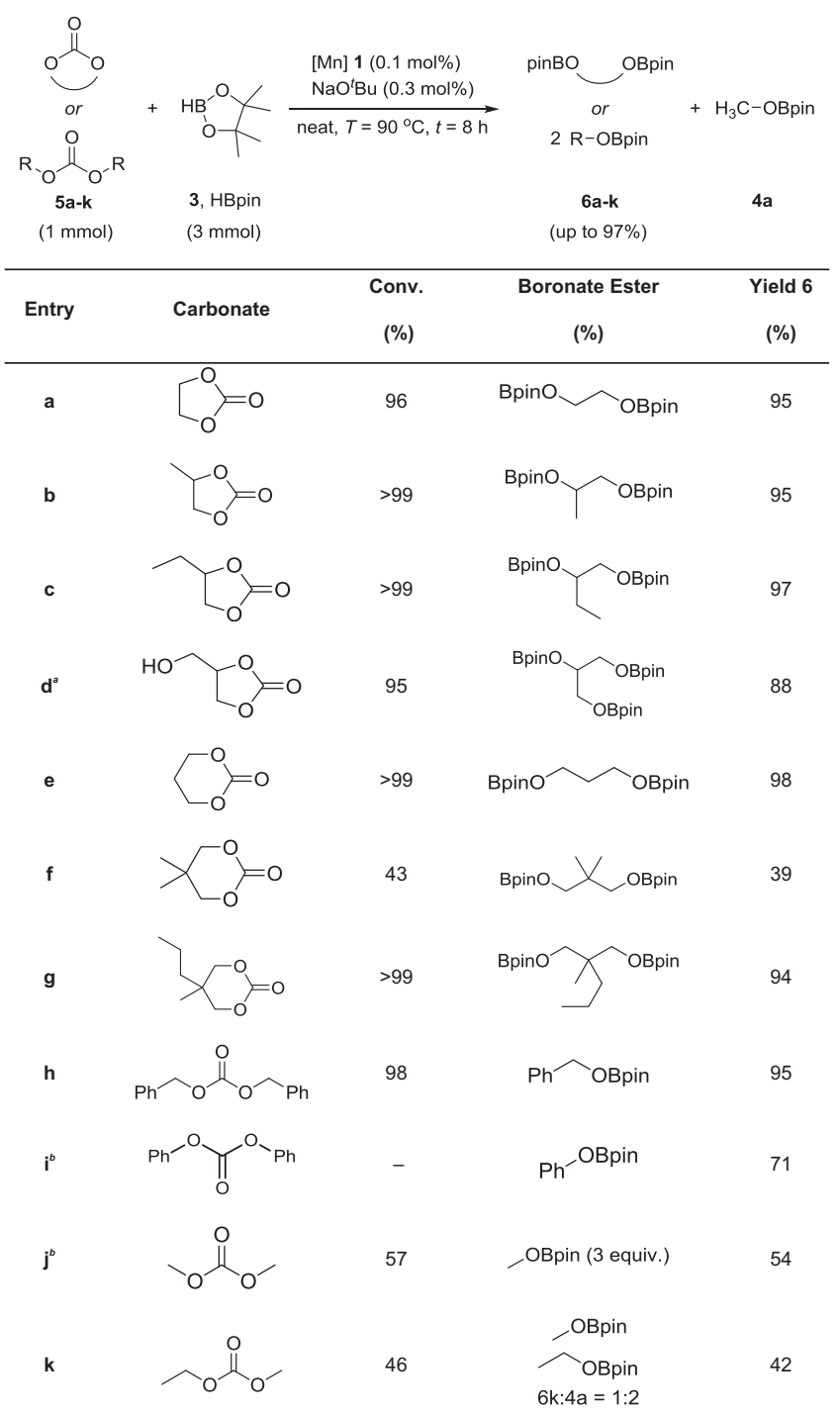


is the byproduct of the industry of vegetable oils, was also reduced to the corresponding boronate ester with $88 \%$ yield. Complex 1 also proved to be highly active for the catalytic hydroboration of six-membered ring carbonates. 1,3-dioxan-2-one (5e) and 5methyl-5-propyl-1,3-dioxan-2-one (5g) gave $98 \%$ and $94 \%$ yield, respectively. The significantly lower yield of $39 \%$ obtained with 5,5-dimethyl-1,3-dioxan-2-one (5f) is probably due to the low solubility of the substrate in pinacolborane.

Linear carbonates are considered to be even more resistant to reduction than their cyclic congeners. Gratifyingly, complex $\mathbf{1}$ was able to catalyze the hydroboration of dibenzyl carbonate (5h) with similar efficiency yielding two equivalents of benzyl boronate in a total of $95 \%$ yield. Diphenyl carbonate (5i) showed $71 \%$ yield to the corresponding boronate ester. Lower conversion was achieved with dimethyl (5j) and ethyl methyl carbonate (5k) which may be due to their solely aliphatic functionality.

Reduction of $\mathrm{CO}_{2}$. The high catalytic activity of the manganese complex 1 in the formation of methyl boronate (4a) from formic acid as well as from various carbonates prompted us to investigate its ability to reduce carbon dioxide directly under the same conditions. The reduction of $\mathrm{CO}_{2}$ to methanol or methanol derivatives is a field of great current interest within strategies to utilize waste carbon dioxide as feedstock at the interface of the energy and chemistry sectors (e.g., carbon capture and utilization, CCU, and power-to-X concepts) ${ }^{38-41}$. The hydroboration of $\mathrm{CO}_{2}$ has been explored in this context using noble and non-noble metal catalyst ${ }^{19,21,42-44}$. In 2010, Guan et al. reported the first hydroboration of $\mathrm{CO}_{2}$ to yield methoxy boronate using a nickel pincer complex showing a turnover number (moles product per moles catalyst, TON) of $495^{45}$. Several noble metal complexes were also reported for the reduction of $\mathrm{CO}_{2}$ to methoxy boronate, but TONs were even lower ${ }^{4,46}$. There is no report currently where the hydroboration of $\mathrm{CO}_{2}$ was achieved using a manganese-based catalyst.

Gratifyingly, complex 1 proved able to catalyze the formation of methyl boronate (4a) using carbon dioxide as feedstock under rather mild conditions similar to those applied for the other substrates. Control experiments demonstrated again that both the $\mathrm{Mn}$ complex and the base were required. Initial experiments were carried out using $0.036 \mathrm{~mol} \%$ of complex 1 and $0.1 \mathrm{~mol} \%$ of $\mathrm{NaO}^{t} \mathrm{Bu}$ dissolved in $2.76 \mathrm{mmol}$ of pinacolborane under ambient pressure of $\mathrm{CO}_{2}$ (from a balloon). The presence of $\mathbf{4 a}$ in solution was verified by NMR spectroscopy, amounting to $76 \%$ based on the HBpin employed after $14 \mathrm{~h}$ at $90{ }^{\circ} \mathrm{C}$ (Table 3, entry 1). These data correspond to a TON of 697 representing already the highest productivity observed for this transformation even under the non-optimized conditions. The reaction occurs with high selectivity and no other $\mathrm{C} 1$ compounds such as formaldehydederivatives, $\mathrm{CO}$ or methane are observed. Complex 1 shows activity also in toluene or THF as solvent, albeit with lower yields. Doubling the amount of catalyst and base amount under solventfree conditions increased product formation to $83 \%$ yield, but of course on expense of the TON. The highest TON was achieved at the original loadings increasing the reaction temperature to $100^{\circ} \mathrm{C}$. This led to nearly quantitative conversion of HBpin (3) giving MeOBpin (4a) in $96 \%$ yield corresponding a TON of 883 .

Mechanistic studies. The reactivity of complex 1 toward HBpin (3) under relevant reaction conditions was investigated in order to get a first insight into its mode of action in these challenging reductive processes. Reacting 1 with $\mathrm{KO}^{t} \mathrm{Bu}$ at room temperature in $\mathrm{d}_{8}$-THF lead to an immediate color change from yellow to dark violet (Fig. 2a). Spectroscopic data confirmed the formation of the unsaturated species I $\left({ }^{31} \mathrm{P}\left\{{ }^{1} \mathrm{H}\right\}\right.$ NMR: $\left.\delta=61.26 \mathrm{ppm}\right)$, in line with the known reactivity of other Mn complexes containing PNPpincer ligands ${ }^{47}$. Addition of pinacolborane 3 to this solution at room temperature restored the yellow color while ${ }^{1} \mathrm{H}$ and ${ }^{31} \mathrm{P}\left\{{ }^{1} \mathrm{H}\right\}$ NMR revealed new signals at $-6.56 \mathrm{ppm}$ (broad, half-width 88 $\mathrm{Hz}$ ) and $65.21 \mathrm{ppm}$, respectively (Fig. 2b). This new species IIa converts slowly to the Mn-hydride complex II, as indicated by appearance of the typical resonances in the ${ }^{1} \mathrm{H}$ NMR and ${ }^{31} \mathrm{P}\left\{{ }^{1} \mathrm{H}\right\}$ NMR spectrum at $\delta=-7.67 \mathrm{ppm}(\mathrm{t}, J=32 \mathrm{~Hz})$ and $\delta=57.87$ ppm, respectively. Heating the solution at $50{ }^{\circ} \mathrm{C}$ for $30 \mathrm{~min}$ lead to a ratio of IIa/II of 90:10 with nearly quantitative conversion to II after standing at room temperature for 2 days (see Supplementary Information for details).

Single crystals suitable for X-ray diffraction of the intermediately formed new complex IIa were obtained by the slow diffusion of hexane into a concentrated solution of dichloromethane (Fig. 2c). The most salient feature of this structure is the four-membered ring $\mathrm{Mn}-\mathrm{H}-\mathrm{B}-\mathrm{N}$ that defines a crucial intermediate during the heterolytic $\mathrm{B}-\mathrm{H}$ bond cleavage across the $\mathrm{Mn}$ amido group. Intermediate IIa showed shorter distance between

Table 3 Hydroboration of $\mathrm{CO}_{2}$ using Mn complex 1 as catalyst

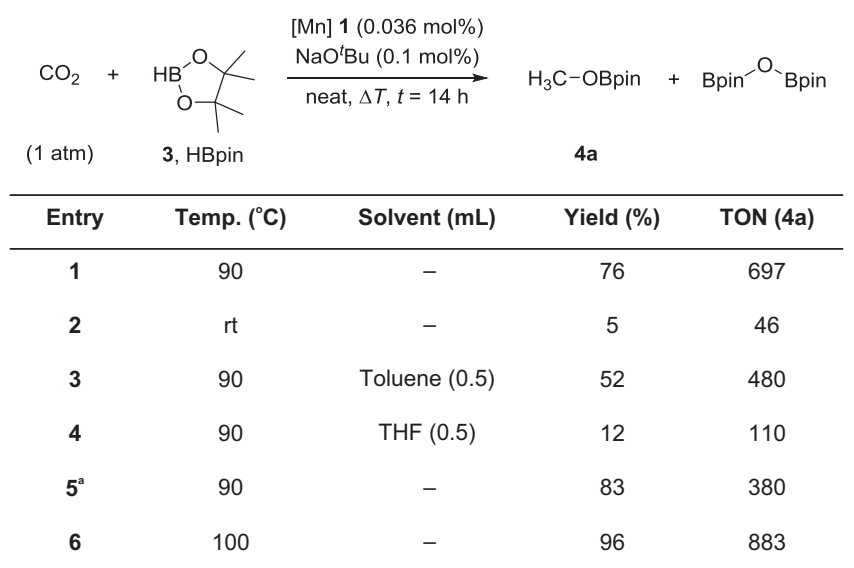

Yields were determined by ${ }^{1} \mathrm{H}$ NMR analysis using mesitylene as internal standard. a, Modified conditions: $\mathrm{CO}_{2}(1 \mathrm{~atm}), \mathbf{1}(0.072 \mathrm{~mol} \%), \mathrm{NaO}{ }^{t} \mathrm{Bu}(0.2 \mathrm{~mol} \%)$ and $\mathbf{3}(2.76 \mathrm{mmol})$ at $90{ }^{\circ} \mathrm{C}$ for $14 \mathrm{~h}$ 
a

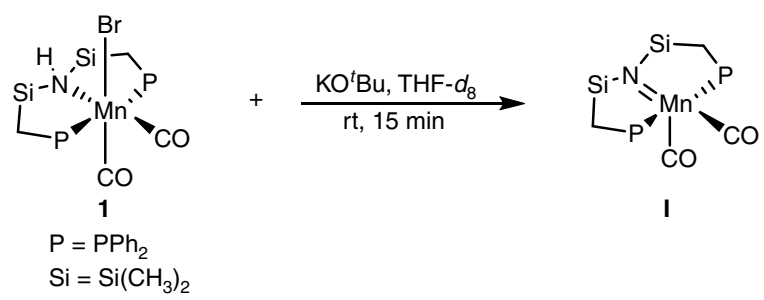

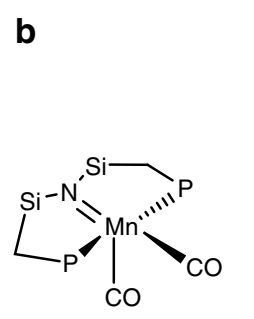

I

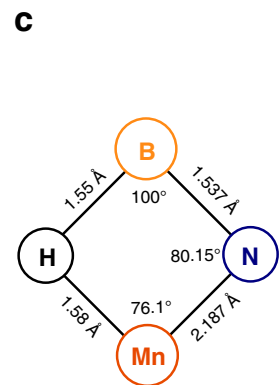

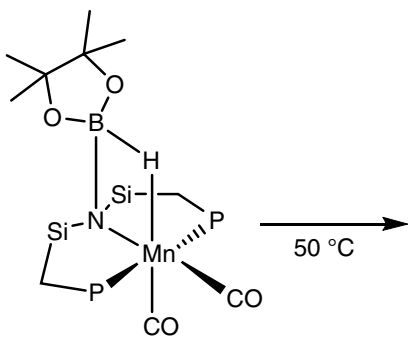

Ila

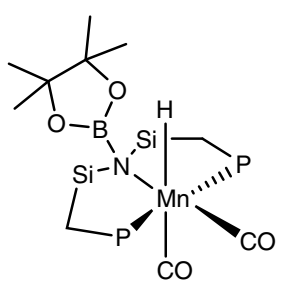

II

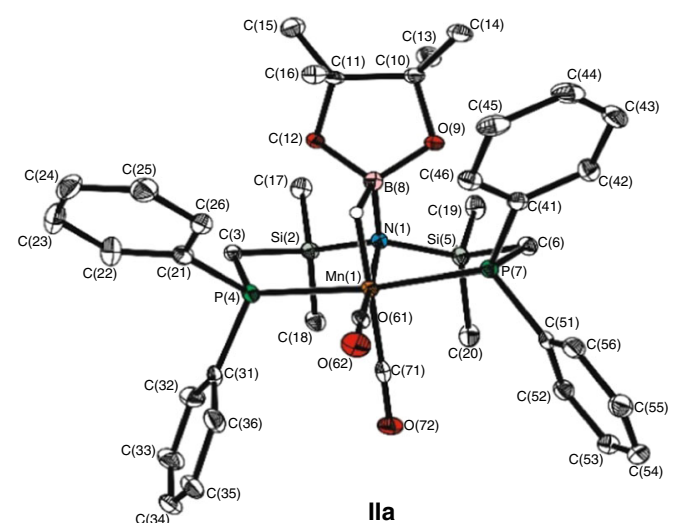

Fig. 2 Generation of potential reaction intermediates and molecular structure of Ila. Overall geometry for Ila: distorted octahedral. Selected angles and atom distances: $\left[\mathrm{P}(4)-\mathrm{Mn}(1)-\mathrm{P}(7)=172.38^{\circ}\right],\left[\mathrm{C}(61)-\mathrm{Mn}(1)-\mathrm{C}(71)=86.73^{\circ}\right],\left[\mathrm{N}(1)-\mathrm{Mn}(1)-\mathrm{P}(4)=88.85^{\circ}\right],\left[\mathrm{N}(1)-\mathrm{Mn}(1)-\mathrm{P}(7)=88.90^{\circ}\right],(\mathrm{Mn}(1)-\mathrm{N}(1)=$ $218.7 \mathrm{pm}),(\mathrm{Mn}(1)-\mathrm{P}(4)=226.93 \mathrm{pm}),(\mathrm{Mn}(1)-\mathrm{P}(7)=226.95 \mathrm{pm}),(\mathrm{N}(1)-\mathrm{Si}(2)=178.1 \mathrm{pm}),(\mathrm{N}(1)-\mathrm{Si}(5)=177.9 \mathrm{pm})$

Manganese and nitrogen atom $(\mathrm{Mn}(1)-\mathrm{N}(1)=218.7 \mathrm{pm})$ in comparison with $1(\mathrm{Mn}(1)-\mathrm{N}(4)=227.4 \mathrm{pm})$. It is, however, longer than $\mathrm{Mn}=\mathrm{N}$ double bonds in complexes with structures analogous to species I (for comparison see the Mn-PNP ${ }^{i P r}$ MACHO-complex: $\mathrm{Mn}-\mathrm{N}, 212.3 \mathrm{pm}, \mathrm{Mn}=\mathrm{N}, 189.0 \mathrm{ppm})^{47}$.

Proposed mechanism. On basis of the experimental observations and current literature precedent in Manganese catalysis, a tentative mechanism for the activation of the $\mathrm{B}-\mathrm{H}$ bond and its transfer to the rather inert $\mathrm{C}=\mathrm{O}$ units using complex $\mathbf{1}$ can be proposed as exemplified for the hydroboration of carbon dioxide in Fig. $3^{48-52}$. In the presence of base, complex 1 reacts to the actual active species I. Reaction with pinacolborane leads to complex IIa with activation of the $\mathrm{B}-\mathrm{H}$ bond. This species may react with carbon dioxide directly or after $\mathrm{B}-\mathrm{H}$ cleavage with hydride species II. Given the slow rate of the $\mathrm{B}-\mathrm{H}$ bond cleavage, we currently favor the direct attack. The hydride complex II could carry an alternative catalytic cycle involving a second molecule of pinacolborane, similar to the mechanism deduced from kinetic studies most recently by Gade et al. for hydroboration of ketones and aldehydes with a Mn-catalyst that cannot form a $\mathrm{Mn}=\mathrm{N}$ unit ${ }^{48}$. In case of pre-catalyst $\mathbf{1}$, an additional open coordination site would have to be provided, e.g., through loss of $\mathrm{CO}$, to enable such a cycle that would bypass the formation of species I and IIa. Although we have currently no evidence to suggest this alternative pathway for pre-catalyst $\mathbf{1}$, the low energy barriers observed with the Gade catalyst indicate that this possibility should be considered in future mechanistic studies also. The carbonyl group can interact with the Lewis acidic boron center, leading to an activation for nucleophilic attack as indicated in intermediate III. The reduced formoxyborane $\mathrm{HC}(\mathrm{O})$ OBpin is liberated to regenerate the active complex I. Subsequently, pinacolborane reacts again with the active species I to give the intermediate IIa. Analogous reduction of the $\mathrm{C}=\mathrm{O}$ unit of the formoxyborane leads to the acetal $\mathrm{H}_{2} \mathrm{C}(\mathrm{OBpin})_{2}$ at this stage, that cleaves into formaldehyde and BpinOBpin. The same steps can be once more repeated with the carbonyl of the formaldehyde unit until it reaches the alcohol/methanol stage. Carbonates can be converted into the corresponding alkyl boronate esters in full analogy, while carboxylic acids can enter the catalytic manifold in form of the boronate derivatives $\mathrm{RC}(\mathrm{O})$ OBpin that are spontaneously formed in presence of HBpin as verified experimentally.

\section{Discussion}

In conclusion, the manganese pincer complex (1) revealed remarkable catalytic activity for the reduction of carboxylic acids, organic carbonates, and $\mathrm{CO}_{2}$ using pinacolborane as the reducing 


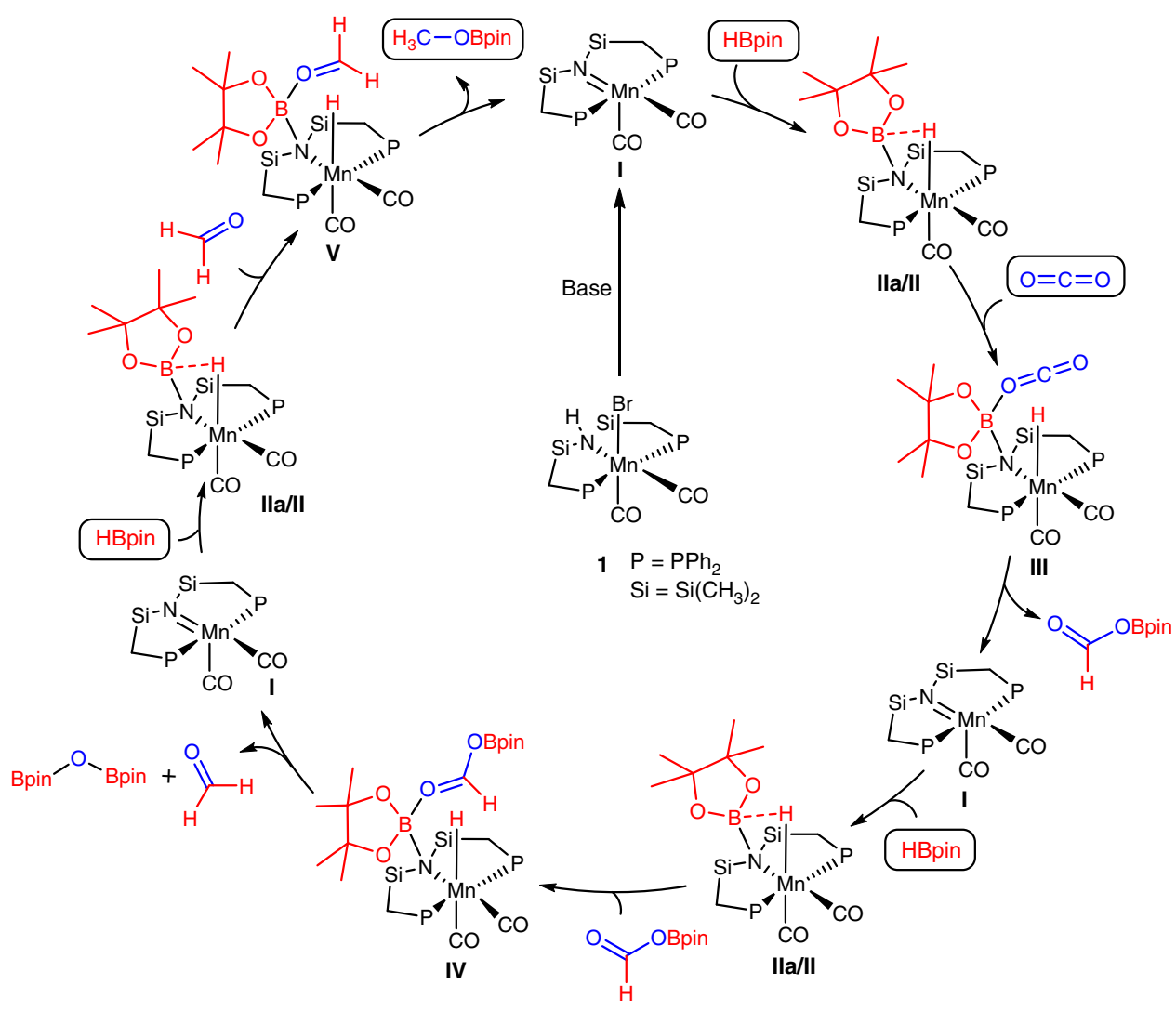

Fig. 3 Suggested reaction mechanism for the hydroboration of $\mathrm{CO}_{2}$ catalyzed by complex 1

agent. The transformation can be applied for a remarkable broad substrate scope. These results significantly enlarge the potential of molecular catalysts based on earth abundant and non-toxic manganese as active metal for de- and re-functionalization of challenging substrates. The synthetic protocols and the molecular insight from this work may thus contribute to the development of benign catalytic systems for sustainable processes including the use of non-fossil carbon feedstocks derived from biomass or carbon dioxide.

\section{Methods}

General procedure for the Mn(I)-catalyzed hydroboration of carboxylic acids. A mixture of [Mn]-precatalyst (1) $(0.2 \mathrm{~mol} \%)$, potassium tert-butoxide $(0.5 \mathrm{~mol} \%)$, pinacolborane (3 eq.), corresponding carboxylic acid (1 eq.) and mesitylene were stirred at $115^{\circ} \mathrm{C}$ for the indicated reaction times. Subsequently, a sample $(15 \mu \mathrm{L})$ of the reaction mixture in $\mathrm{CDCl}_{3}(0.5 \mathrm{~mL})$ was subjected to ${ }^{1} \mathrm{H}-\mathrm{NMR}$ spectroscopy to determine the yield in alkyl boronate ester.

General procedure for the $\mathbf{M n}(\mathrm{I})$-catalyzed hydroboration of carbonates. Carbonate (5) $(1 \mathrm{mmol})$ was added at room temperature to a mixture of [Mn]precatalyst $(1)(0.1 \mathrm{~mol} \%), \mathrm{NaO}^{t} \mathrm{Bu}(0.3 \mathrm{~mol} \%)$ and pinacolborane $(3 \mathrm{mmol})$. The reaction mixture was then heated at $90^{\circ} \mathrm{C}$ for $8 \mathrm{~h}$. Afterwards, the reaction medium was cooled down to room temperature, and mesitylene was added as an internal standard. Subsequently, a sample $(10 \mu \mathrm{L})$ of the reaction mixture in $\mathrm{CDCl}_{3}(0.4$ $\mathrm{mL}$ ) was subjected to ${ }^{1} \mathrm{H}$-NMR spectroscopy to determine the yield in alkyl boronate ester.

General procedure for the $\mathrm{Mn}(\mathrm{I})$-catalyzed hydroboration of carbon dioxide. Carbon dioxide was purged three times through a schlenk containing a mixture of [Mn]-precatalyst (1) (0.73 mg, $0.036 \mathrm{~mol} \%), \mathrm{NaO}^{t} \mathrm{Bu}(0.288 \mathrm{mg}, 0.1 \mathrm{~mol} \%)$ and pinacolborane $(353.2 \mathrm{mg}, 2.76 \mathrm{mmol})$ in the indicated solvent. Afterwards, the schlenk tube was equipped with a $\mathrm{CO}_{2}$ balloon and the reaction mixture was heated at the indicated temperatures. The reaction medium was then cooled down to room temperature, and mesitylene was added as an internal standard. Subsequently, a sample $(10 \mu \mathrm{L})$ of the reaction mixture in $\mathrm{CDCl}_{3}(0.4 \mathrm{~mL})$ was subjected to ${ }^{1} \mathrm{H}$ NMR spectroscopy to determine the yield in alkyl boronate ester.

\section{Data availability}

The X-ray crystallographic data for the structure of complex (1) and (IIa) have been deposited at the Cambridge Crystallographic Data Centre (CCDC) under the deposition numbers CCDC 1868572 and 1868571, respectively. These data can be obtained free of charge via www.ccdc.cam.ac.uk/data_request/cif. The authors declare that all data supporting the findings of this study are available within the manuscript and its Supplementary Information files. All other data are available from the authors upon reasonable request.

Received: 8 September 2018 Accepted: 28 September 2018 Published online: 30 October 2018

\section{References}

1. Erythropel, H. C. et al. The Green ChemisTREE: 20 years after taking root with the 12 principles. Green. Chem. 20, 1929-1961 (2018).

2. Bryan, M. C. et al. Green chemistry articles of interest to the pharmaceutical industry. Org. Process Res. Dev. 21, 1464-1477 (2017).

3. Crabtree, R. H. An organometallic future in green and energy chemistry? Organometallics 30, 17-19 (2011).

4. Leitner, W., Klankermayer, J., Pischinger, S., Pitsch, H. \& Kohse-Hoinghaus, K. Advanced biofuels and beyond: chemistry solutions for propulsion and production. Angew. Chem. Int. Ed. 56, 5412-5452 (2017).

5. Tuck, C. O., Perez, E., Horvath, I. T., Sheldon, R. A. \& Poliakoff, M. Valorization of biomass: deriving more value from waste. Science 337, 695-699 (2012).

6. Corma, A., Iborra, S. \& Velty, A. Chemical routes for the transformation of biomass into chemicals. Chem. Rev. 107, 2411-2502 (2007).

7. Klankermayer, J., Wesselbaum, S., Beydoun, K. \& Leitner, W. Selective catalytic synthesis using the combination of carbon dioxide and hydrogen: catalytic chess at the interface of energy and chemistry. Angew. Chem. Int. Ed. 55, 7296-7343 (2016).

8. Liu, Q., Wu, L., Jackstell, R. \& Beller, M. Using carbon dioxide as a building block in organic synthesis. Nat. Commun. 6, 5933 (2015).

9. Wang, W. H., Himeda, Y., Muckerman, J. T., Manbeck, G. F. \& Fujita, E. $\mathrm{CO}_{2}$ Hydrogenation to formate and methanol as an alternative to photo- and electrochemical $\mathrm{CO}_{2}$ reduction. Chem. Rev. 115, 12936-12973 (2015). 
10. Das Neves Gomes, C. et al. A diagonal approach to chemical recycling of carbon dioxide: organocatalytic transformation for the reductive functionalization of $\mathrm{CO}_{2}$. Angew. Chem. Int. Ed. 51, 187-190 (2012).

11. Obligacion, J. V. \& Chirik, P. J. Earth-abundant transition metal catalysts for alkene hydrosilylation and hydroboration. Nat. Rev. Chem. 2, 15-34 (2018).

12. Filonenko, G. A., van Putten, R., Hensen, E. J. M. \& Pidko, E. A. Catalytic (de) hydrogenation promoted by non-precious metals - Co, Fe and $\mathrm{Mn}$ : recent advances in an emerging field. Chem. Soc. Rev. 47, 1459-1483 (2018).

13. Kumar, A., Janes, T., Espinosa-Jalapa, N. A. \& Milstein, D. Manganese catalyzed hydrogenation of organic carbonates to methanol and alcohols. Angew. Chem. Int. Ed. 57, 12076-12080 (2018).

14. Leitner, W., Kaithal, A. \& Markus, H. Catalytic hydrogenation of cyclic carbonates using manganese complexes. Angew. Chem. Int. Ed., https://doi. org/10.1002/anie.201808676 (2018)

15. Zubar, $\mathrm{V}$., et al Hydrogenation of $\mathrm{CO}_{2}$-derived carbonates and polycarbonates to methanol and diols by metal-ligand cooperative manganese catalysis. Angew. Chem. Int. Ed., https://doi.org/10.1002/anie.201805630 (2018).

16. Tamang, S. R. \& Findlater, M. Cobalt catalysed reduction of $\mathrm{CO}_{2}$ via hydroboration. Dalton. Trans. 47, 8199-8203 (2018).

17. Dubey, A., Nencini, L., Fayzullin, R. R., Nervi, C. \& Khusnutdinova, J. R. Bioinspired $\mathrm{Mn}(\mathrm{I})$ complexes for the hydrogenation of $\mathrm{CO}_{2}$ to formate and formamide. ACS Catal. 7, 3864-3868 (2017).

18. Bertini, F. et al. Carbon dioxide hydrogenation catalysed by well-defined $\mathrm{Mn}$ (I) PNP pincer hydride complexes. Chem. Sci. 8, 5024-5029 (2017).

19. Murphy, L. J. et al. Selective Ni-catalyzed hydroboration of $\mathrm{CO}_{2}$ to the formaldehyde level enabled by new PSiP ligation. Organometallics 36, 3709-3720 (2017).

20. Wang, D. \& Astruc, D. The golden age of transfer hydrogenation. Chem. Rev. 115, 6621-6686 (2015).

21. Shintani, R. \& Nozaki, K. Copper-catalyzed hydroboration of carbon dioxide. Organometallics 32, 2459-2462 (2013).

22. Laitar, D. S., Muller, P. \& Sadighi, J. P. Efficient homogeneous catalysis in the reduction of $\mathrm{CO}_{2}$ to CO. J. Am. Chem. Soc. 127, 17196-17197 (2005).

23. Espinosa-Jalapa, N. A. et al. Manganese-catalyzed hydrogenation of esters to alcohols. Chem. Eur. J. 23, 5934-5938 (2017)

24. Papa, V. et al. Efficient and selective hydrogenation of amides to alcohols and amines using a well-defined manganese-PNN pincer complex. Chem. Sci. 8, 3576-3585 (2017).

25. Kelly, C. M., McDonald, R., Sydora, O. L., Stradiotto, M. \& Turculet, L. A manganese pre-catalyst: mild reduction of amides, ketones, aldehydes, and esters. Angew. Chem. Int. Ed. 56, 15901-15904 (2017).

26. Ma, X., Zuo, Z., Liu, G. \& Huang, Z. Manganese-catalyzed asymmetric hydrosilylation of aryl ketones. ACS Omega 2, 4688-4692 (2017).

27. Maji, B. \& Barman, M. Recent developments of manganese complexes for catalytic hydrogenation and dehydrogenation reactions. Synthesis 49, 3377-3393 (2017).

28. Garbe, M., Junge, K. \& Beller, M. Homogeneous catalysis by manganese-based pincer complexes. Eur. J. Org. Chem. 2017, 4344-4362 (2017).

29. Elangovan, S. et al. Efficient and selective N-alkylation of amines with alcohols catalysed by manganese pincer complexes. Nat. Commun. 7, 12641 (2016).

30. Zhang, G. et al. Highly selective hydroboration of alkenes, ketones and aldehydes catalyzed by a well-defined manganese complex. Angew. Chem. Int. Ed. 55, 14369-14372 (2016).

31. Fryzuk, M. D., MacNeil, P. A., Rettig, S. J., Secco, A. S. \& Trotter, J. Tridentate amidophosphine derivatives of the nickel triad: synthesis, characterization, and reactivity of nickel(II), palladium(II), and platinum(II) amide complexes. Organometallics 1, 918-930 (1982).

32. Kisan, S., Krishnakumar, V. \& Gunanathan, C. Ruthenium-catalyzed deoxygenative hydroboration of carboxylic acids. ACS Catal. 8, 4772-4776 (2018).

33. Schaffner, B., Schaffner, F., Verevkin, S. P. \& Borner, A. Organic carbonates as solvents in synthesis and catalysis. Chem. Rev. 110, 4554-4581 (2010).

34. Han, Z. et al. Catalytic hydrogenation of cyclic carbonates: a practical approach from $\mathrm{CO}_{2}$ and epoxides to methanol and diols. Angew. Chem. Int. Ed. 51, 13041-13045 (2012).

35. Balaraman, E., Gunanathan, C., Zhang, J., Shimon, L. J. \& Milstein, D. Efficient hydrogenation of organic carbonates, carbamates and formates indicates alternative routes to methanol based on $\mathrm{CO}_{2}$ and CO. Nat. Chem. 3, 609-614 (2011).

36. Laserna, V. et al. Carbon dioxide as a protecting group: highly efficient and selective catalytic access to cyclic cis-diol scaffolds. Angew. Chem. Int. Ed. 53, 10416-10419 (2014)
37. Crich, D., Vinod, A. U. \& Picione, J. The 3,4-O-carbonate protecting group as a beta-directing group in rhamnopyranosylation in both homogeneous and heterogeneous glycosylations as compared to the chameleon-like 2,3-Ocarbonates. J. Org. Chem. 68, 8453-8458 (2003).

38. Artz, J. et al. Sustainable conversion of carbon dioxide: an integrated review of catalysis and life cycle assessment. Chem. Rev. 118, 434-504 (2018).

39. Mac Dowell, N., Fennell, P. S., Shah, N. \& Maitland, G. C. The role of $\mathrm{CO}_{2}$ capture and utilization in mitigating climate change. Nat. Clim. Change 7, 243-249 (2017)

40. Aresta, M., Dibenedetto, A. \& Angelini, A. Catalysis for the valorization of exhaust carbon: from $\mathrm{CO}_{2}$ to chemicals, materials, and fuels. technological use of $\mathrm{CO}_{2}$. Chem. Rev. 114, 1709-1742 (2014).

41. Centi, G., Quadrelli, E. A. \& Perathoner, S. Catalysis for $\mathrm{CO}_{2}$ conversion: a key technology for rapid introduction of renewable energy in the value chain of chemical industries. Energy Environ. Sci. 6, 1711-1731 (2013).

42. Li, L., Zhu, H., Liu, L., Song, D. \& Lei, M. A hydride-shuttle mechanism for the catalytic hydroboration of $\mathrm{CO}_{2}$. Inorg. Chem. 57, 3054-3060 (2018).

43. Liu, T. et al. Hydroboration of $\mathrm{CO}_{2}$ catalyzed by bis(phosphinite) pincer ligated nickel thiolate complexes. Dalton. Trans. 46, 4504-4509 (2017).

44. Bontemps, S., Vendier, L. \& Sabo-Etienne, S. Borane-mediated carbon dioxide reduction at ruthenium: formation of $\mathrm{C} 1$ and $\mathrm{C} 2$ compounds. Angew. Chem. Int. Ed. 51, 1671-1674 (2012).

45. Chakraborty, S., Zhang, J., Krause, J. A. \& Guan, H. An efficient nickel catalyst for the reduction of carbon dioxide with a borane. J. Am. Chem. Soc. 132, 8872-8873 (2010).

46. Sgro, M. J. \& Stephan, D. W. Frustrated Lewis pair inspired carbon dioxide reduction by a ruthenium tris(aminophosphine) complex. Angew. Chem. Int. Ed. 51, 11343-11345 (2012).

47. Fu, S., Shao, Z., Wang, Y. \& Liu, Q. Manganese-catalyzed upgrading of ethanol into 1-butanol. J. Am. Chem. Soc. 139, 11941-11948 (2017).

48. Vasilenko, V., Blasius, C. K. \& Gade, L. H. One-pot sequential kinetic profiling of a highly reactive manganese catalyst for ketone hydroboration: leveraging sigma-bond metathesis via alkoxide exchange steps. J. Am. Chem. Soc., https:// doi.org/10.1021/jacs.8b05340 (2018).

49. Garbe, M. et al. Manganese(I)-catalyzed enantioselective hydrogenation of ketones using a defined chiral PNP pincer ligand. Angew. Chem. Int. Ed. 56, 11237-11241 (2017)

50. Nguyen, D. H. et al. Manganese pincer complexes for the base-free, acceptorless dehydrogenative coupling of alcohols to esters: development, scope, and understanding. ACS Catal. 7, 2022-2032 (2017).

51. Khusnutdinova, J. R. \& Milstein, D. Metal-ligand cooperation. Angew. Chem Int. Ed. 54, 12236-12273 (2015)

52. Anaby, A. et al. B-H bond cleavage via metal-ligand cooperation by dearomatized ruthenium pincer complexes. Organometallics 33, 3716-3726 (2014).

\section{Acknowledgements}

We gratefully acknowledge basic support by the MPG and RWTH Aachen University. The results summarized here have been assembled as part of our activities in the Cluster of Excellence Tailor-made Fuels from Biomass (EXC 236, TMFB) (reduction of biogenic acids), the Kopernikus Project Power-to-X (03SFK2A, reduction of $\mathrm{CO}_{2}$ ) and the BMBF project Carbon2Chem (03EK3041D, reduction of acetic acid). A.K. thanks the Erasmus Mundus Action 1 Programme SINCHEM (FPA2013-0037) for a fellowship.

\section{Author contributions}

A.K. developed the synthetic protocol for catalytic hydroboration of carbonates and $\mathrm{CO}_{2}$, carried out the NMR studies for the reactivity of complex (1), and isolated species IIa for Xray crystallography. He provided analysis and data for manuscript and contributed to the writing of the draft. S.S. synthesized and characterized the pincer ligand and Mn complex (1) and isolated complex (1) for X-ray crystallography. He supported the experiments for catalyst screening and providing analysis and data for manuscript draft. C.E. developed the synthetic protocol for the hydroboration of carboxylic acids, provided analysis and data for manuscript draft, and contributed to writing of manuscript draft. T.W. carried out X-ray diffraction and crystal structure analysis and provided the data for manuscript draft. M.H. supervised part of the project work including the planning of experiments. He contributed to the writing of the manuscript draft for the mechanistic discussion. C.W. supervised part of the project work including planning of experiments. He supervised data analysis, especially for spectroscopic data and mechanistic interpretation of experimental data. He also supervised writing of the draft manuscript and assembly of SI. W.L. was responsible for the basic project definition and the conceptual planning of experimental work-flow. He conceived the mechanistic interpretation of experimental data. He was directing the general publication strategy and writing of the manuscript. 


\section{Additional information}

Supplementary Information accompanies this paper at https://doi.org/10.1038/s41467018-06831-9.

Competing interests: The authors declare no competing interests.

Reprints and permission information is available online at http://npg.nature.com/ reprintsandpermissions/

Publisher's note: Springer Nature remains neutral with regard to jurisdictional claims in published maps and institutional affiliations. (c) (i) Open Access This article is licensed under a Creative Commons Attribution 4.0 International License, which permits use, sharing, adaptation, distribution and reproduction in any medium or format, as long as you give appropriate credit to the original author(s) and the source, provide a link to the Creative Commons license, and indicate if changes were made. The images or other third party material in this article are included in the article's Creative Commons license, unless indicated otherwise in a credit line to the material. If material is not included in the article's Creative Commons license and your intended use is not permitted by statutory regulation or exceeds the permitted use, you will need to obtain permission directly from the copyright holder. To view a copy of this license, visit http://creativecommons.org/ licenses/by/4.0/.

(C) The Author(s) 2018 